\title{
Experiment and Study On Effect Of Sludge External Reflux Ratio On The Dosage Of Micro Vortex clarifier
}

\author{
Hu Feng-ping ${ }^{1, a}$,Huang Bi-xia ${ }^{2, b}$, Ji Dan $^{3, c}$ \\ ${ }^{1,2,3}$ school of civil engineering and architecture,East China Jiao Tong University,Nanchang \\ University, China \\ ahufengping1968@126.com,,huangbbxx1993.163.com, ${ }^{\mathrm{c}} 272688062 @ q q . c o m$
}

\begin{abstract}
Key words:micro vortex clarifier, external sludge reflux,reflux ratio, dosage
Abstract: In order to solve some problemsabout selectingblindly and randomly design and operational parameters ofmicro vortex clarifier .By studying the raw water from Kongmu-Lake, this experimentchooses PAC as thebest coagulant,and its best dosage is $25 \mathrm{mg} / \mathrm{L}$. Meanwhile the influence of micro vortex clarifierdosagein different sludge external reflux ratiois researched. Experiments are conducted in three kinds of refluxratios respectively $10 \%, 30 \%$ and $50 \%$. Inlet flow is $10 \mathrm{~m}^{3} / \mathrm{h}$, the flocculation time is $6.8 \mathrm{mins}$, adding the quantity of PAC gradually increased from $20 \mathrm{mg} / \mathrm{L}$ to $45 \mathrm{mg} / \mathrm{L}$, when external reflux ratio is $30 \%$, micro vortex clarifier has the best treatment effect. The lowest turbidity, total phosphorus, $\mathrm{COD}_{\mathrm{Mn}}$ and ammonia nitrogenof the water are respectively $0.376 \mathrm{NTU}, 0.102 \mathrm{mg} / \mathrm{L}, 2.44 \mathrm{mg} / \mathrm{L}, 7.76 \mathrm{mg} / \mathrm{L}$. At this time, the best dosage is 30 $\mathrm{mg} / \mathrm{L}$, and the best reflux ratio is $30 \%$. The test provides scientific data to support the application of micro vortex clarification technology.
\end{abstract}

\section{Introduction}

For traditional clarifier have encountered in the operation of the bottleneck problem such as high cost and inefficiency, basing on the micro-whirling reactor, East China Jiaotong University research team respectively develop the micro vortex clarifier[1], which has been widely used in recent years, and achieved good social benefits and economic benefits[2]. However due to the studies about micro vortex flocculation mechanism and key technology[3] are not comprehensive and thoroughly, and in the practical engineering application, for the selection of design and operational parameters is relatively blind and random, which hinders the further expansion of the technology in water treatment engineering.Especially for micro vortex clarification process in terms of return sludge's influence on the treatment effect[4], remains to be further studied, so as to provide guidance for the production practice and fully excavate the potential of micro vortex clarification process. By researching the influence of dosage of micro vortex clarifier in different sludge external reflux ratio, it provides scientific data support for popularization and application of micro vortex clarifier treatment process.

\section{Materials and methods}

\subsection{Testing apparatus}

In this test, the micro vortex clarifier is on the basis of the traditional hydraulic circulating clarifier, belongs to the sludge circular clarifying pool. The tank of micro vortex clarifier is made of PE plastic, including flocculation reaction unit and inclined tube sedimentation separation unit. As shown in figure 1. 

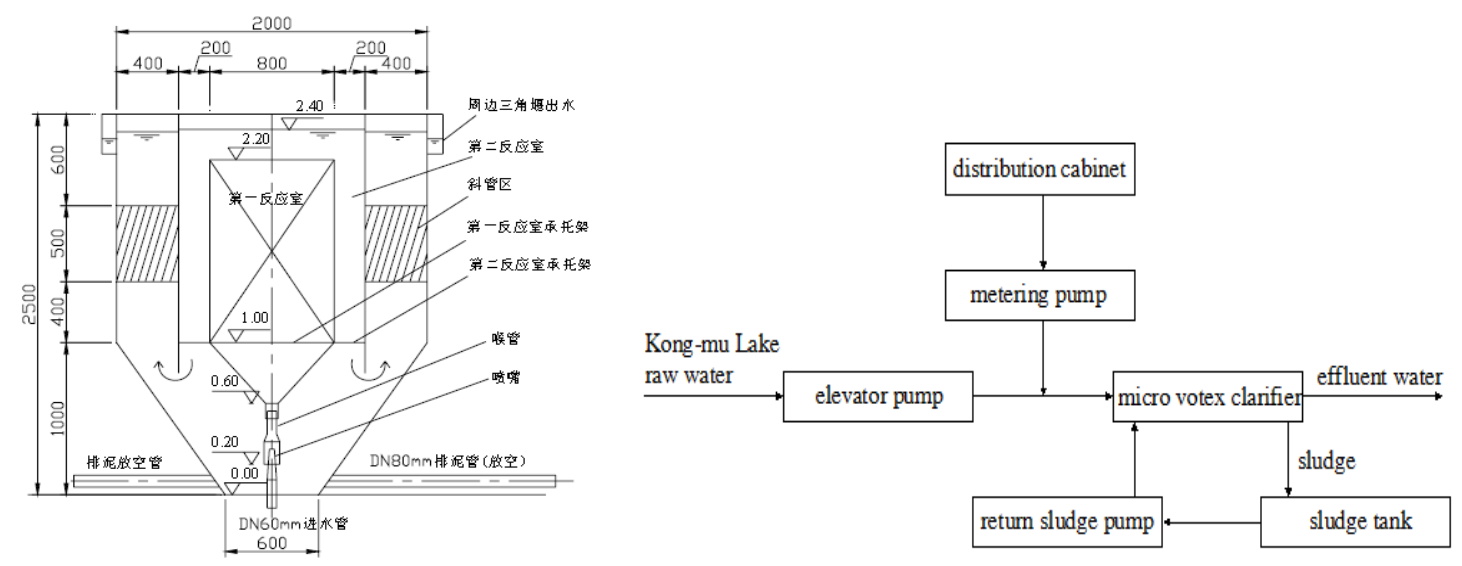

Fig.1 Schematic Diagrae Whirlingm of th ClarifierFig.2 Flow diagram of process 2.2Technological process

The process is shown in figure 2.

\section{Results and Discussion}

Test is conducted on the condition of the inlet flow is $10 \mathrm{~m}^{3} / \mathrm{h}$ and the flocculating time is 6.8 min,at three kinds of reflux ratio, respectively $10 \%, 30 \%, 50 \%$, and the dosing amount of coagulant is $20 \mathrm{mg} / \mathrm{L}, 25 \mathrm{mg} / \mathrm{L}, 30 \mathrm{mg} / \mathrm{L}, 35 \mathrm{mg} / \mathrm{L}, 40 \mathrm{mg} / \mathrm{L}$ and $45 \mathrm{mg} / \mathrm{L}$ respectively. By measuring the inflow water and effluent water's water turbidity, TP, $\mathrm{COD}_{\mathrm{Mn}}$ and $\mathrm{NH}_{3}-\mathrm{N}$ of micro vortex clarification pool, comparing the treatment effect and reach a conclusion that the influence of dosage of micro vortex clarifierin different sludge external reflux ratio.

1)Under different sludge external reflux ratio, the influence of the dosing amount of coagulant on turbidity, as shown in figure 3.

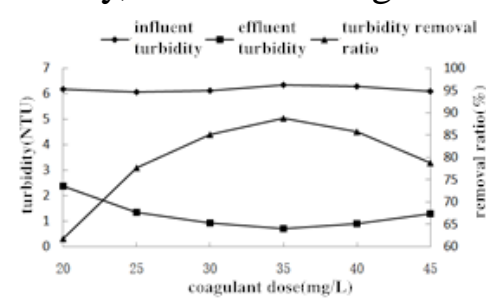

(a)

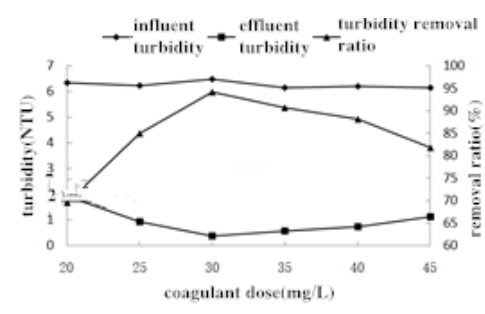

(b)

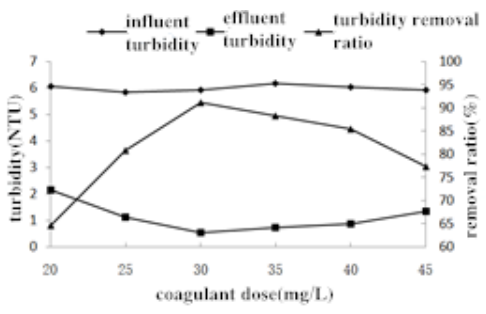

(c)

Fig.3 Turbidity removalin different dosage By Sludge RecycleRatioof 10\%,30\%,50\%

The figure 3 shows that with the increase of coagulant dosage, under different reflux ratio, effluent turbidity are increased at first and then decreased. Different sludge reflux ratio have an effect on the treatment effect of turbidity. When the reflux ratio is $10 \%, 30 \%, 50 \%$ respectively, the effluent turbidity of micro vortex clarifier are $0.711 \mathrm{NTU}, 0.376 \mathrm{NTU}, 0.525 \mathrm{NTU}$, the biggest removal ratio can reach $88.76 \%, 94.19 \%$ and $88.76 \%$ respectively, the corresponding coagulant dosage are $35 \mathrm{mg} / \mathrm{L}, 30 \mathrm{mg} / \mathrm{L}, 30 \mathrm{mg} / \mathrm{L}$ separately. In conclusion, from the perspective of the removal efficiency of turbidity, when the sludge external reflux ratio is $10 \%$, the removal effect is the worst, and $30 \%$ is the best.

2)Under different sludge external reflux ratio, the influence of the dosing amount of coagulant on TP, as shown in figure 4.

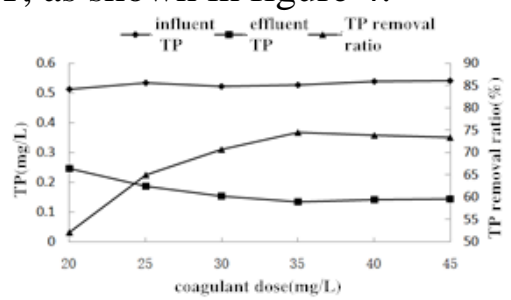

(a)

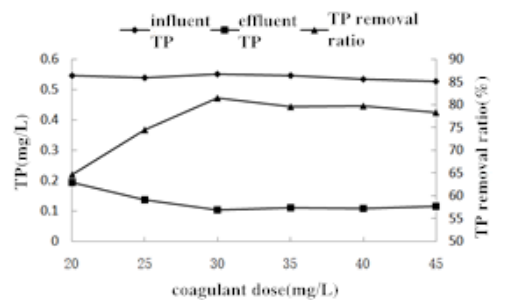

(b)

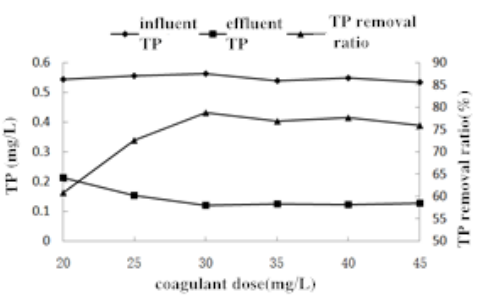

(c)

Fig.4TPremovalin different dosage By Sludge Recycle Ratioof 10\%,30\%,50\% 
The figure 4 shows that within the experimental range of coagulant dosage, the effluent TP ofmicro vortex clarifier is relatively stable.Different sludge reflux ratio have an effect on the treatment effect of TP. When the reflux ratio is $10 \%, 30 \%, 50 \%$ respectively, the effluent TP of micro vortex clarifier are $0.134 \mathrm{mg} / \mathrm{L}, 0.102 \mathrm{mg} / \mathrm{L}, 0.119 \mathrm{mg} / \mathrm{L}$, the biggest removal ratio can reach $74.57 \%, 81.52 \%$ and $78.83 \%$ respectively, the corresponding coagulant dosage are 35mg/L, 30mg/L, 30mg/L separately.

When the sludge external reflux ratio is $30 \%$, the removal effect of TP is the best.

3)Under different sludge external reflux ratio, the influence of the dosing amount of coagulant on $\mathrm{COD}_{\mathrm{Mn}}$, as shown in figure 5 .
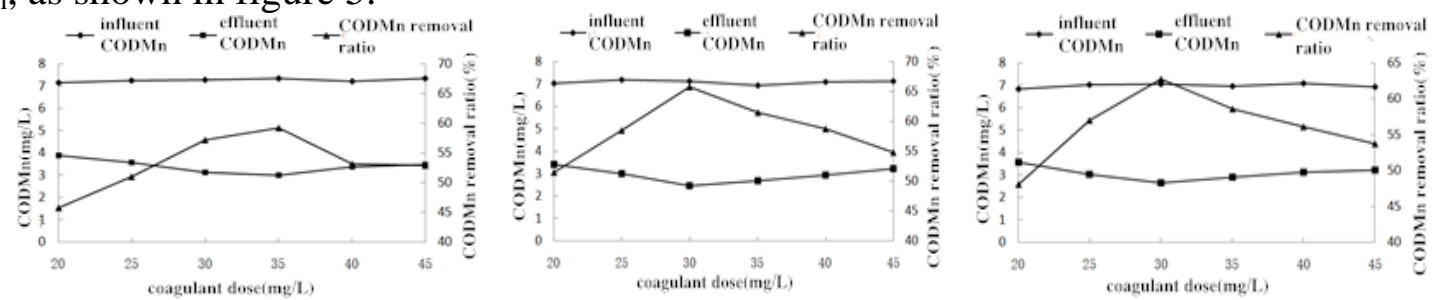

(a) (b) (c)

Fig.5COD ${ }_{\mathrm{Mn}}$ removalin different dosage By Sludge RecycleRatioof 10\%,30\%,50\%

The figure 5 shows that with the increase of coagulant dosage, under different reflux ratio, effluent $\mathrm{COD}_{\mathrm{Mn}}$ are decreased at first and then increased. Different sludge reflux ratio have an effect on the treatment effect of $\mathrm{COD}_{\mathrm{Mn}}$. When the reflux ratio is $10 \%, 30 \%, 50 \%$ respectively, the effluent $\mathrm{COD}_{\mathrm{Mn}}$ of micro vortex clarifier are $2.99 \mathrm{mg} / \mathrm{L}, 2.44 \mathrm{mg} / \mathrm{L}, 2.63 \mathrm{mg} / \mathrm{L}$, the biggest removal ratio can reach $59.21 \%, 65.73 \%$ and $62.75 \%$ respectively, the corresponding coagulant dosage are $35 \mathrm{mg} / \mathrm{L}, 30 \mathrm{mg} / \mathrm{L}, 30 \mathrm{mg} / \mathrm{L}$ separately.

4)Under different sludge external reflux ratio, the influence of the dosing amount of coagulant on $\mathrm{NH}_{3}-\mathrm{N}$, as shown in figure 6 .

The figure 6 shows that with the increase of coagulant dosage, under different reflux ratio, effluent $\mathrm{NH}_{3}$-Nare decreased at first and then increased. Different sludge reflux ratio have an effect on the treatment effect of $\mathrm{NH}_{3}-\mathrm{N}$. When the reflux ratio is $10 \%, 30 \%, 50 \%$ respectively, the effluent $\mathrm{NH}_{3}-\mathrm{N}$ of micro vortex clarifier are $8.02 \mathrm{mg} / \mathrm{L}, 7.76 \mathrm{mg} / \mathrm{L}, 8.33 \mathrm{mg} / \mathrm{L}$, the biggest removal ratio can reach $11.96 \%, 14.35 \%$ and $12.22 \%$ respectively, the corresponding coagulant dosage are $35 \mathrm{mg} / \mathrm{L}$, $30 \mathrm{mg} / \mathrm{L}, 30 \mathrm{mg} / \mathrm{L}$ separately. As you can see, under three different sludge external reflux ratio, the removal effects of $\mathrm{NH}_{3}-\mathrm{N}$ is not very ideal, this is because the micro vortex clarification process is poor in removing dissolved pollutant, and NH3 - $\mathrm{N}$ in raw water is mostly exist in the form of dissolved state.

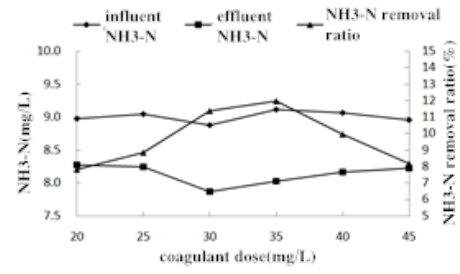

(a)

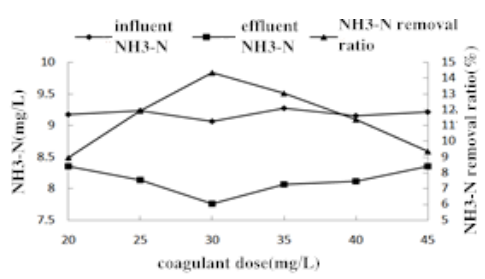

(b)

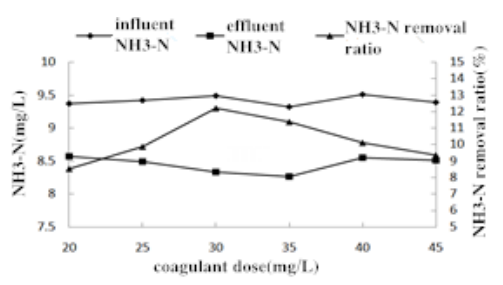

(c)

Fig.6 $\mathrm{NH}_{3}-\mathrm{N}$ removalin different dosage By Sludge RecycleRatioof 10\%,30\%50\%

To sum up, different external reflux ratio have an good effects on treating the raw water of Kong-mu Lake. Among them, when the external reflux ratio is $30 \%$, and coagulant dosage is 30 $\mathrm{mg} / \mathrm{L}$, the removal effect of turbidity, TP, CODMn, $\mathrm{NH}_{3}-\mathrm{N}$ is the best; When the external reflux ratio is $50 \%$, and coagulant dosage is $35 \mathrm{mg} / \mathrm{L}$, the removal effect is better; When the external reflux ratio is $10 \%$, and coagulant dosage is $35 \mathrm{mg} / \mathrm{L}$, the removal effect is the worst.

\section{Conclusion}

When inlet flow of micro vortex clarifieris $10 \mathrm{~m}^{3} / \mathrm{h}$, the flocculating time is $6.8 \mathrm{~min}$, dosing amount of coagulant PAC gradually increased from $20 \mathrm{mg} / \mathrm{L}$ to $45 \mathrm{mg} / \mathrm{L}$ andexternal sludge reflux ratio is 
$30 \%$, the treatment effect is the best.On the condition of the optimum dosage is $30 \mathrm{mg} / \mathrm{L}$, the lowest effluent water turbidity, TP, $\mathrm{COD}_{\mathrm{Mn}}, \mathrm{NH}_{3}-\mathrm{N}$ are $0.376 \mathrm{NTU}, 0.102 \mathrm{mg} / \mathrm{L}, 2.44 \mathrm{mg} / \mathrm{L}, 7.76 \mathrm{mg} / \mathrm{L}$ respectively.

\section{Acknowledgments}

This work was financially supported by JiangXi Province Natural Science Foundation (No 20151BAB203030),the Natural Science Foundation of China (NSFC)(No61272197), Landing Plan of Scientific and Technological Project of Jiangxi Provincial Colleges and Universities (KJLD2013037) and Cultivation Plan of Leadership for Excellence Jiangxi Province and Poyang Lake 555 Engineering(S2013-57).

\section{Reference}

[1] Zhen-gongTong, Feng-ping Hu. The development and application of integrated vortex grid clarification technology [J].China Water \& Wastewater, 2010, 26(6):63-68.

[2] Zhen-gong Tong, Yong-zhong Fang, Feng-ping Hu.Micro vortex clarification technology used in a water treatment works in Ji-mo[J].China Water \& Wastewater,2008,(04):66-68

[3]Jr-Lin Lin, Chihpin Huang, Ching-Ju M.Chin, Jill R. Pan.Coagulation dynamics of fractal flocs induced by enmeshment and electrostatic patch mechanisms[J]. Water Research, 2008,42(17):4457-4466.

[4]Ming Rao, Long an Cao, Yan Zuo et al. Testing about preoxidation joint with return sludge processing dealing with slightly polluted and low turbidity water[J]. Water supply technology, 2010, 4(2): 12-14. 